\title{
CONTRACEPTIVE AWARENESS AMONG MARRIED PREGNANT WOMEN FROM URBAN AND RURAL AREAS ATTENDING ANTENATAL CLINIC IN A TERTIARY HOSPITAL IN WEST BENGAL
}

\author{
Alpana Chhetri1, Sanjay Vashisth ${ }^{2}$ \\ ${ }^{1}$ Assistant Professor, Department of obstetrics and Gynaecology, CSS College of Obstetrics and Gynaecology and Child Health, Kolkata, \\ West Bengal, India. \\ ${ }_{2}^{2}$ Associate Professor, Department of Physiology, Midnapore Medical College, Paschim Medinipur, West Bengal, India.
}

\section{ABSTRACT}

\section{BACKGROUND}

Our hospital CSS College of Obstetrics, Gynaecology and Child Health, Kolkata is a tertiary referral centre and a teaching ho spital and caters to around $65 \%$ of the urban and $35 \%$ of the rural population.

Aim: This led us to study the knowledge, attitude and practice regarding contraception among married pregnant women attending antenatal clinic and further counsel them regarding future contraception during the antenatal period.

\section{MATERIALS AND METHODS}

This cross-sectional study was conducted in the outpatient department of Obstetrics and Gynaecology in patients attending antenatal clinic for the first time from May 2018 to July 2018. Out of 400 patients, 350 patients gave the consent to fill up the questionnaire form. Out of 350 women, $230(65.7 \%)$ belonged to the urban group and $120(34.3 \%)$ belonged to the rural group. Regarding education level, $6.6 \%$ females were uneducated in the rural group and $4.7 \%$ women were uneducated in the urban group. It was seen that $15 \%$ in the rural group and $11.7 \%$ in the urban group were not using contraception. The unmet need of contraception was $11 \%$ in rural group and $9 \%$ in urban group. The unmet need was more in the uneducated women in both groups and in low socioeconomic status. The level of higher education level in urban group showed more confidence in natural methods of contraception. There was also less acceptability of contraceptive methods like pills in urban population.

Study Design- Questionnaire based.

\section{RESULTS}

It was seen that $15 \%$ in the rural group and $11.7 \%$ in the urban group were not using contraception. The unmet need of contraception was $11 \%$ in rural group and $9 \%$ in urban group. The unmet need was more in the uneducated women in both groups and in low socioeconomic status. The level of higher education level in urban group showed more confidence in natural methods of contraception. There was also less acceptability of contraceptive methods like pills in urban population.

\section{CONCLUSION}

The unmet need can be improved in both populations by increasing knowledge and availability of more effective methods of contraception for spacing of pregnancies. Women should be given liberty in choosing an appropriate method and both the husband and wife should be included in counselling. Methods to reduce population explosion along with healthy mother and child have been recently focused on birth spacing. Since $99 \%$ of deliveries are institutional, advantage of creating awareness, proper and effective counselling regarding contraception should be provided during her antenatal visits.

\section{KEY WORDS}

Awareness, Contraceptive, Married, Pregnant, Unmet Need, Urban, Rural.

HOW TO CITE THIS ARTICLE: Chhetri A, Vashisth S. Contraceptive awareness among married pregnant women from urban and rural areas attending antenatal clinic in a tertiary hospital in West Bengal. J. Evolution Med. Dent. Sci. 2018;7(43):4609-4612, DOI: $10.14260 /$ jemds/2018/1028

\section{BACKGROUND}

In 1952, India launched a nation-wide family planning programme to reduce fertility and stabilise the population growth. During that time, natural method of family planning was the most appropriate technique of limiting births. In 1965, there was a paradigm shift toward Lippes loop and government took different measures to promote it and since then great revolution has taken place in family planning measures.

'Financial or Other Competing Interest': None.

Submission 24-09-2018, Peer Review 09-10-2018,

Acceptance 12-10-2018, Published 22-10-2018.

Corresponding Author:

Dr. Alpana Chhetri,

Flat No. E209, Sunrise Estate,

14/C, Radhanath Chowdhury Road,

Kolkata-700015, West Bengal, India.

E-mail: chhetrialpana@yahoo.com

DOI: $10.14260 /$ jemds $/ 2018 / 1028$

\section{(c) $(1) \ominus$}

Even with high awareness of contraception, there occurs a large gap between the knowledge and practice of those methods due to existing variations in the demography and geography of India. There are many social taboos, myths and ignorance which are responsible for huge number of unwanted pregnancies and abortions. Even with increasing rate of education among women, the practice of contraception still takes a backseat.

Around $30 \%$ of the pregnant mothers attending the OPD of our hospital are due to unplanned pregnancy. Our study emphasised this lack of awareness of contraception among the general population and counsels them about various methods of available contraceptive measure and their choice to pick up any of available methods in future.

\section{MATERIALS AND METHODS}

This cross-sectional study of our method of study was questionnaire based on demographic profile regarding age, 
religion, socio-economic status, education, awareness of contraception, types of methods, source of knowledge and its side effects and to compare between the rural and the urban groups. The period of study was from May 2018 to July 2018. Out of 400 pregnant women attending antenatal clinic of our hospital, only 350 gave consent for the study. Data were analysed by simple percentages. They were also counselled regarding various options of contraception available for spacing and limiting births and the consent for their future contraceptive choice noted. Sample size was taken as conveniences. Since the duration of the study was few months. The patients were selected by conveniences.

\section{RESULTS}

Table 1 shows $35 \%$ of the mothers were between $21-25$ years of age in rural group and $33.9 \%$ were there in urban group between the ages 21 - 25 years.

\begin{tabular}{|c|c|c|}
\hline Age & Rural (n= 120) & Urban (n= 230) \\
\hline$<20$ & $12.50 \%$ & $10.40 \%$ \\
\hline $21-25$ & $35 \%$ & $33.90 \%$ \\
\hline $26-30$ & $25 \%$ & $26.90 \%$ \\
\hline $31-35$ & $17.50 \%$ & $21.70 \%$ \\
\hline$>35$ & $10 \%$ & $7.10 \%$ \\
\hline \multicolumn{2}{|c|}{ Table 1. Distribution of Women according to their Age } \\
\hline
\end{tabular}

Table 2 shows that $66.6 \%$ in rural group belonged to low socio-economic conditions and $63 \%$ in urban group belonged to low socio-economic status.

\begin{tabular}{|c|c|c|}
\hline Socioeconomic Status & Rural & Urban \\
\hline Lower & $66.60 \%$ & $63 \%$ \\
\hline Middle & $30.80 \%$ & $31.30 \%$ \\
\hline Upper & $2.60 \%$ & $5.70 \%$ \\
\hline \multicolumn{2}{|c|}{ Table 2. Socio-economic Status of the Study Group } \\
\hline
\end{tabular}

Table 3 shows that in the rural group 50.8\% were Hindus, 41.6\% Muslims and 7.6\% belonged to Christianity and other religions. In the urban class 50\% were Hindus, $40.8 \%$ were Muslims and $9.2 \%$ belonged to Christianity and other religions. Use of contraceptives was high among Hindus in both rural and urban group, and less among Muslims and Christians.

\begin{tabular}{|c|c|c|c|c|}
\hline Religion & Rural & $\begin{array}{c}\text { Not Using } \\
\text { (Rural) }\end{array}$ & Urban & $\begin{array}{c}\text { Not Using } \\
\text { (Urban) }\end{array}$ \\
\hline Hindu & $54.10 \%$ & $21.00 \%$ & $52.17 \%$ & $19.00 \%$ \\
\hline Muslim & $33.30 \%$ & $43.00 \%$ & $39.10 \%$ & $42.00 \%$ \\
\hline $\begin{array}{c}\text { Christianity and } \\
\text { Others }\end{array}$ & $12.50 \%$ & $36.00 \%$ & $8.69 \%$ & $39.00 \%$ \\
\hline \multicolumn{4}{|c|}{ Table 3. Distribution according to Religion } \\
\hline
\end{tabular}

Table 4 shows that $6.6 \%$ of women in rural and $4.7 \%$ women in urban group were uneducated. It is observed that users of contraception were directly proportional to the level of education and $50 \%$ in rural and $45.45 \%$ in urban areas who did not use contraception were uneducated.

\begin{tabular}{|c|c|c|c|c|}
\hline $\begin{array}{c}\text { Education } \\
\text { Levels }\end{array}$ & Rural & $\begin{array}{c}\text { Rural } \\
\text { (Not Using) }\end{array}$ & Urban & $\begin{array}{c}\text { Urban } \\
\text { (Not Using) }\end{array}$ \\
\hline Uneducated & $6.60 \%$ & $50 \%$ & $4.70 \%$ & $45.45 \%$ \\
\hline $\begin{array}{c}\text { Primary } \\
\text { educated }\end{array}$ & $63.30 \%$ & $13.15 \%$ & $48.20 \%$ & $13.60 \%$ \\
\hline $\begin{array}{c}\text { Secondary } \\
\text { educated }\end{array}$ & $26.60 \%$ & $9.37 \%$ & $40 \%$ & $6.52 \%$ \\
\hline Higher educated & $3.50 \%$ & $2.5 \%$ & $7.10 \%$ & $5.80 \%$ \\
\hline
\end{tabular}

Table 4. Distribution according to the Educational Status

Table 5 shows $5.5 \%$ women in the rural group and $3.7 \%$ of women in urban group had never known about contraception. It was also seen that $15 \%$ of the women from rural area and $11.7 \%$ from urban area were not using contraception and among them around $60 \%$ in both groups were planning pregnancy. Among those using contraception, majority of the women in both rural and urban group used oral contraceptive pills and major number of women in urban group relied upon natural methods of contraception. Condoms were used as a form of contraception in $20 \%$ of rural women and in $17.3 \%$ urban women. Emergency or postcoital pills were used in $4.3 \%$ of rural women and $6.4 \%$ of urban females. The knowledge of the women regarding emergency contraceptives was very poor. Majority of the women did not know the timeframe in which it had to be taken.

\begin{tabular}{|c|c|c|}
\hline Usage of Contraceptives & Rural & Urban \\
\hline Not Using & $15 \%$ & $11.70 \%$ \\
\hline Natural Methods & $11.60 \%$ & $17.30 \%$ \\
\hline Condoms & $20 \%$ & $17.30 \%$ \\
\hline OCP & $33.30 \%$ & $30 \%$ \\
\hline Injectables & $5.80 \%$ & $7.80 \%$ \\
\hline IUD & $10 \%$ & $9.50 \%$ \\
\hline Emergency Contraceptives & $4.30 \%$ & $6.40 \%$ \\
\hline Table 5. Usage of different types of Contraceptives \\
\hline
\end{tabular}

Table 6 shows the source of information in both groups. $93 \%$ of women in urban group and $88 \%$ of women in rural group had at least heard about one method of contraception.

\begin{tabular}{|c|c|c|}
\hline & Rural & Urban \\
\hline TV & $10 \%$ & $13.04 \%$ \\
\hline Radio & $10.80 \%$ & $12.17 \%$ \\
\hline Newspaper/ Magazine & $11.60 \%$ & $14.30 \%$ \\
\hline Health Professional & $17.50 \%$ & $10.40 \%$ \\
\hline NGO & $10.80 \%$ & $11.30 \%$ \\
\hline Family & $14.10 \%$ & $13.90 \%$ \\
\hline Friends & $15 \%$ & $15.20 \%$ \\
\hline Others & $10 \%$ & $9.50 \%$ \\
\hline
\end{tabular}

Table 6. Source of Information on Contraceptives

Regarding the source of information regarding contraception it is observed that health professional provided a major role in delivering contraceptive awareness in rural areas, whereas in urban women friends followed by media were the source of information regarding contraceptives.

In Graph 1, we can see that apart from planning to become pregnant knowledge of gap was the most common cause of not using contraceptives in rural group and fear of side effects was most common for not using contraceptives in the urban group. 


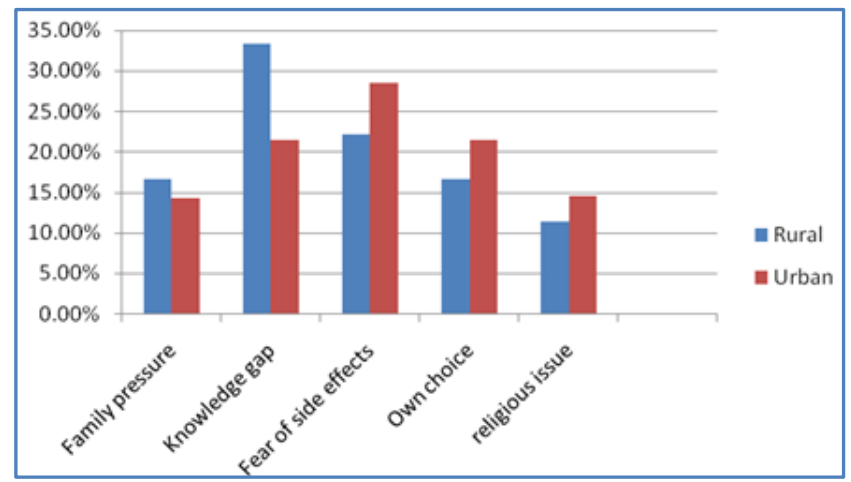

Graph 1. Reasons for not using Contraceptives

At the end of the questionnaire, the women along with her husband were counselled about the need of contraception and a basket of choice of various types of contraceptive methods were offered. The family planning counselors and the doctors who counsel the women after discussing different options avaliable took informed choice and the consent.

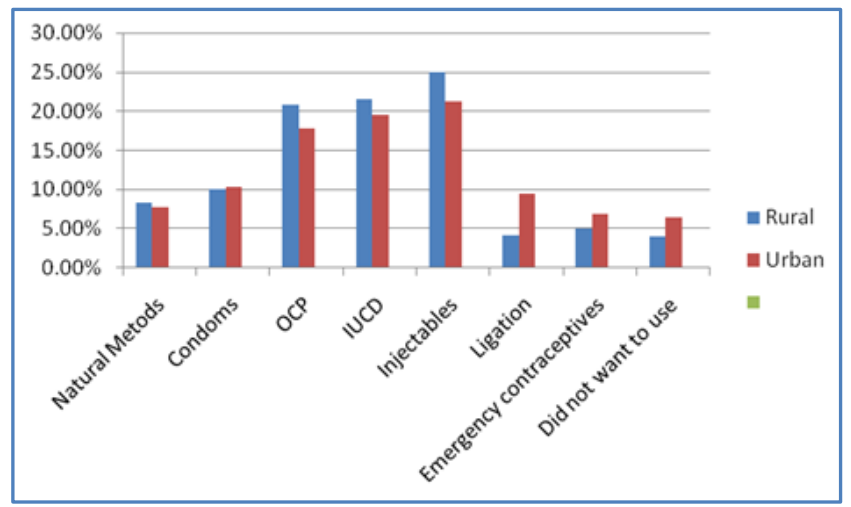

Graph 2. Contraceptive Choices opted by the couple for Future Contraception

Graph 2 shows the majority of the women from both urban and rural areas opted for injectable contraceptives followed by intrauterine device and oral contraceptive pills. Only $4.1 \%$ in the rural group and $6.5 \%$ in the urban group did not chose any contraceptives.

\section{DISCUSSION}

In our study, most of the responders were in the age group of 20 - 21 years (35\% in rural and 33.9\% in urban). Study conducted by Prachi ${ }^{1}$ et al showed $47.6 \%$ respondents in the age group of 25 to 34 years.

A study conducted by Donati ${ }^{2}$ et al in Manipur concluded that Muslims had low rates of contraceptive use $17 \%)$ and Hindus (62\%) even after controlling for education. In our study, $43 \%$ of Muslims in rural area and $42 \%$ of Muslims in urban area did not practice contraception in comparison to $21 \%$ of Hindus in rural and $19 \%$ of Hindus in urban area.

Gautam $^{3}$ et al found that rise in education helps in improving acceptance of contraceptive methods. Study done by Shah ${ }^{4}$ also reported women's education is an important variable, as the use of contraceptive method is significantly increased from $43 \%$ in women with primary education to $70 \%$ in secondary and higher educated women. In our study, use of contraception increases from $86 \%$ in women with primary education to $93 \%$ in secondary and higher education group.

In our study, $93 \%$ of women from urban area and $88 \%$ of women from rural area had heard about atleast one type of contraceptive method. In other studies the percentage of awareness varied from $94 \%$ in Pakistan ${ }^{5}, 94.2 \%$ in Sikkim and $100 \%$ in Bangladesh.

In our study contraceptive awareness in women of rural areas were mainly by health professionals like ASHA workers and in women from urban areas. Contraceptive awareness was through friends and mass media like televisions, radio, newspapers and magazines. Srivastava ${ }^{6}$ et al's study showed $70 \%$ of women had gained contraceptive knowledge from friends and family and 39\% from televisions and radio. In a study done by Jain DC, the knowledge of temporary methods of spacing was poor among rural group. The low literacy status and limited availabilty of mass media compared to urban group plays an important role in creating awareness.

In a study conducted in rural areas of West Bengal by Biswas $^{7}$ et al in 1994 showed that the reason for nonacceptance of contraceptive use was fear of side effects in $22.6 \%$ women. In our study the majority of women from rural area not using contraception was due to lack of knowledge, whereas in urban women the reason for non-use of contraceptive was the fear of side effects.

The use of Emergency contraceptives in our study was $4.3 \%$ among women in rural group and $6.4 \%$ in urban group, but their knowledge regarding the timeframe was very poor. Studies conducted by Krishna Dahiya ${ }^{8}$ et al showed $12.2 \%$ of the respondents were aware of Emergency contraceptives and majority of them were not clear about the exact timeframe it had to be taken.

In a study conducted by Hernandez ${ }^{9}$ et al, it was observed that antepartum contraception counseling increases the use of contraception post-partum. Women whose pregnancy was unintended were significantly more likely to use contraception post-partum, if they received pre-natal counseling. In our study, $93 \%$ - $96 \%$ of the respondents opted to use and consented for some form of contraception post delivery.

Approximately, $13 \%$ of currently married women between ages 18 - 49 in India have unmet need for contraception according to International Institute of Population Sciences (IIPS). In our study, the unmet need in rural group is $11 \%$ and in urban group is $9 \%$.

\section{CONCLUSION}

There is a need to motivate both husband and wife to adopt contracetion and explain them the benefits of spacing of pregnancies and small family norm. The unmet need of contraception may be improved by improving the literacy rate, contraceptive counseling and easy availability of contraceptives.

\section{REFERENCES}

[1] Prachi R, Das GS, Ankur B, et al. A study of knowledge, attitude and practice of family planning among the women of reproductive age group in Sikkim. J Obstet Gynecol India 2008;58(1):63-7. 
[2] Donati S, Sharma N, Medda E, et al. Family planning knowledge, attitude and practice (KAP) survey in Manipure state. J Obstet Gynecol India 2003;53(5):485-90.

[3] Gautam AC, Seth PK. Appraisal of the knowledge, attitude and practices (KAP) of family control devices among rural Rajputs and scheduled castes of Hatwar area of Bilaspur district, Himachal Pradesh, India. The Anthropologist 2002;4(4):289-92.

[4] Shah NM. Past and current contraceptive use in Pakistan. Stud Fam Plann 1979;10(5):164-73.

[5] Zafar MI, Ford N, Ankomah A. Significance of beliefs and values predicting fertility and contraceptive behavior in Pakistan. J Biol Soc Sci 1995;27(34):30118.
[6] Srivastava R, Srivastava DK, Jina R, et al. Contraceptive knowledge, attitude and practice (KAP) survey. J Obstetric Gynecol India. 2005;55(6):546-50.

[7] Biswas AK, Roy A, Biswas R. Adoption of small family norm in rural community of West Bengal. Indian J Community Med 1994;19(2):68-71.

[8] Dahiya K, Mann S, Nanda S. Women's knowledge and opinions regarding emergency contraception. J South Asian Feder Obstet Gynae 2012;4(3):151-4.

[9] Hernandez LE, Sappenfield WM, Goodman D, et al. Is effective contraceptive useconceived prenatally in Florida? An association between pre natal contraceptive counseling and postpartum contraceptive use. Matern Child Health J 2012;16(2):423-9. 